\title{
Anfis ve Bulanık K Ortalamalar İle Kalp Hastalı̆̆ının Tespit edilmesi
}

\author{
Mesut POLATGIL \\ Milli Eğitim Bakanlığı, Sivas, Türkiye \\ mesutbiyan@gmail.com \\ (Geliş/Received:04.05.2020; Kabul/Accepted:14.10.2020) \\ DOI: $10.17671 /$ gazibtd. 731678
}

\begin{abstract}
Özet - Dünyada ölüm oranları bakımından kalp hastalıkları üst sıralarda yer almaktadır. Önümüzdeki yıllarda kalp hastalıklarından dolayı ölenlerin sayısının daha da artacağı belirtilmektedir. Kalp hastalıklarında tek olumlu yön ise bu hastalıkların önlenebilir olmasıdır. Hastalıkların önlenmesi bakımından son yıllarda makine öğrenmesi gibi yöntemler sıklıkla kullanılmaktadır. Bugüne kadar farklı yöntemlerle gerçekleştirilmiş birçok çalışma ve farklı başarı oranları bulunmaktadır. Bu çalışmada, kalp hastalıklarının tahmin edilmesinde Anfis (Adaptive Neuro-Fuzzy Inference System) ve Bulanık K Ortalamalar yöntemlerinin bir arada kullanıldığı ve başarı oranının ciddi düzeyde artırıldığı yeni bir yöntem önerilmektedir. Çalışmada veriler öncelikle Bulanık K Ortalamalar ile kümelendirilmiştir. Daha sonra elde edilen küme üyelik değerleri Anfis sisteminin modellenmesi ve eğitiminde kullanılmıştır. Verilerin beş bulanık kümeye ayrılması ile elde edilen sonuçların Anfis sisteminin başarısını ciddi düzeyde artırdığ görülmüştür. K kat çaprazlama yöntemi ile test edilen sistemin başarı oranı \%9835 olarak tespit edilmiştir. Elde edilen sonuçlar literatürde aynı veri seti ile gerçekleştirilen çalışmalarla kıyaslanmıştır. Sonuç olarak bu çalışmada önerilen yöntemin doğru sınıflandırma oranı ile kalp hastalıkları tahmininde kullanılabileceği düşünülmektedir.
\end{abstract}

Anahtar Kelimeler — kalp hastalıkları, anfis, bulanık k ortalamalar, makine öğrenmesi.

\section{Detection of Heart Disease with Anfis and Fuzzy C Means}

\begin{abstract}
In terms of death rates in the world, heart diseases are at the top. It is stated that the number of people who died from heart diseases will increase in the coming years. The only positive aspect of heart diseases is that these diseases can be prevented. In terms of preventing diseases, methods such as machine learning are frequently used in recent years. There are many studies conducted with different methods and different success rates until today. In this study, a new method is proposed in which the Anfis ((Adaptive Neuro-Fuzzy Inference System)) and Fuzzy C Means are used together to predict heart diseases and the success rate is increased significantly. In the study firstly, the data were clustered with Fuzzy C Means. Then, the cluster membership values were used in the modeling and training of the Anfis system. The results obtained by dividing the data five two fuzzy clusters have been found to significantly increase the success of the ANFIS system. The success rate of the system, which has been tested with $\mathrm{K}$ fold cross method, has been determined as \% 9835. The obtained results were compared with the studies performed with the same dataset in the literature. As a result, it is thought that the method proposed in this study can be used in estimating heart diseases with its accuracy classification rate.
\end{abstract}

Keywords - heart diseases, anfis, fuzzy c means, machine learning.

\section{GİRIŞ (INTRODUCTION)}

Vücudumuzdaki organlar hayatsal faaliyetleri devam ettirmemizde belirli görevler üstlenmişlerdir. $\mathrm{Bu}$ organlardan kalbimiz, anne karnında iken ilk oluşan, 6.
Haftadan itibaren atmaya başlayan ve diğer organların kalp ve damar sistemi etrafinda meydana gelmesi bakımından oldukça özel ve önemli bir organdır. Kalbimiz ortalama olarak dakikada 70, günde 104.000 
ve yılda 38 milyon kez kasılarak, içindeki kanı vücudumuza pompalamaktadır [1].

Kalp, damar, atardamar ve toplardamarlarımızın tümü kardiyovasküler sistem olarak bilinir. Kardiyovasküler sistemde yaşanacak sorunlar, yüksek tansiyon, damar tıkanıklığı, koroner kalp hastalığı ve felç gibi hastalıkların oluşmasına neden olacaktır. Kalp insan yaşamının devam ettirilmesinde oldukça önemli bir rol oynayan ve kardiyovasküler sistem için çok kritik bir organdır. Bu organ yapısında zamanla meydana gelen aksaklıklar kardiyovasküler hastalık (KVH) oluşmasına neden olmaktadır. Dünya Sağlık Örgütü'ne göre gerçekleşen ölümlerin nedenlerine bakıldığında $\mathrm{KVH}$ çeşitlerinin oldukça yaygın olduğu görülmektedir. Her y1l 17 milyondan fazla insan KVH dolayısı ile ölmektedir. $\mathrm{Bu}$ sayı tüm dünya ölümlerinin \%31'ine denk gelmektedir. KVH çeşitleri arasında ki ciddi sorunlardan olan kalp hastalıklarından dolayı, 2016 yılında 15,2 milyon ölümle dünyanın önündeki en ciddi sorun olarak ortaya çıkmıştır. Bunların yanında, Dünya Sağlık Örgütü, önümüzdeki on yıllık süreçte kalp hastalığına bağlı ölümlerde sayının 23,6 milyona ulaşacağı tahmin etmektedir [2]. Böylesine ciddi bir ölüm nedeni olan kalp hastalığı riskini azaltmak için önlem alınması gerektiği ortadadır. Zaten ölüm oranlarındaki olumlu olan önemli etken, KVH hastalıkların önlenebilecek olmalarıdır. Hastalık teşhisi tıpta zor bir görevdir. Teşhis genellikle bir hastanın bulgu, semptom ve fizik muayenesi sonuçlarının analizi ile olmaktadır. Fakat burada da hem doktor hem de hasta kaynaklı olabilecek bazı faktörlerden dolayı teşhis ve tedavi süreçlerinde sıkıntılar olabilmektedir [3].

Kalp hastalığının kesin tanısı ve hastalık şiddetinin saptanması için çeşitli uygulamalar ve yöntemler vardır. Veri madenciliği, yapay zekâ ya da makine öğrenmesi gibi yöntemlerin kullanıldığı klinik karar destek sistemlerinin oluşturulması son yıllarda üzerinde oldukça fazla çalışılan konulardan biridir. $\mathrm{Bu}$ yöntemlerin kullanıldığı çalışmalarda da önemli derecede başarı oranları elde edilmiştir. $\mathrm{Bu}$ çalışmalarda özellikle UCI veritabanından elde edilen veriler üzerinde çeşitli öznitelik seçme yöntemleri ve makine öğrenmesi algoritmaları kullanılarak başarı sonuçları verilmiştir. Bu aynı veritabanını kullanan çalışmalar içerisinde C\# programı ile arayüz oluşturma [4], farklı algoritma sonuçlarının karşılaştırılması üzerine oluşturulan [5] [6], yapay sinir ağı ve bulanık sinir ağının birlikte kullanılması [7], karar ağacı algoritmalarının farklı çeşitlerinin uygulanması [8], cep telefonu tabanlı giyilebilir bir cihaz ile mobil kontrollü uygulaması olan [9], hastalardan verilerin anketlerle alınması [10] gibi çalışmalar farklı yöntem ve başarı oranları ile literatürde yer almaktadır. $\mathrm{Bu}$ çalışmalar incelendiğinde yüzde olarak 60 ile 92 arasında kalp hastalıklarının tespit edilebildiği belirtilmektedir. Ancak kalp hastalıkları gibi insan sağlığı ile ilgili konularda bu başarı oranlarının artırılması hayati önem taşımaktadır. Literatürde Anfis yöntemini kullanarak başarının yüzde 92,30 olarak belirlendiği çalışma bulunmaktadır [11]. Fakat bu çalışmada 13 öznitelikten sadece 7 tanesinin kullanıldığ 1 ve bunların niçin kullandığının belirtilmediği görülmüştür. $\mathrm{Bu}$ yüzden hem tüm özniteliklerin kullanılması hem de başarı oranının daha da artırılması bu çalışmanın literatüre katkısı olacağı düşünülmektedir. Ayrıca bu çalışmada hem Anfis hem de Bulanık K Ortalamalar yöntemi bir arada kullanıldığından dolayı bulanık mantık tabanlı çalışan iki farklı yöntemin bir arada kullanılarak daha güçlü bir yap1 elde edilmesi çalışmanın önemli bir noktasıdır. Bulanık Mantık yaklaşımı ve bu yaklaşımı temel alan yöntemler ile ilgili olarak farklı alanlarda birçok çalışma gerçekleştirilmiştir. $\mathrm{Bu}$ alanlar muhasebe çalışmalarından sağlık çalışmalarına kadar çeşitlilik göstermektedir [12-14]. Farklı alanlarda yapılan bu çalışmalarda başarı sonuçlarının yüksek olması da ayrıca önemlidir. Örneğin, Anfis ile yapılan çalışmalardan Hisse senedi getirileri yüzde doksan üzerinde bir başarı elde edilmesi [15], prostat kanseri mikroarray gen ifade problemini analiz etmek için Anfis sistemi yine yüzde doksan üzerinde bir sınıflandırma başarısı göstermiştir [16], enerji sistemleri ve su kaynaklarının modellenmesinde kullanılarak Anfis ile yine yüksek başarı bulunmuştur [17]. Bulanık K Ortalamalar kümeleme yönteminin de literatürde yaygın olarak kullanılmaktadır [18-20]. Bu çalışma literatürde Anfis ve Bulanık K Ortalama ile gerçekleştirilen ve yüksek başarı sonuçları elde eden bu çalışmalar temelinde iki yöntemin bir arada kullanılmasının daha etkin sonuçlar verebileceğini göstermek amacı ile gerçekleştirilmiştir.

\subsection{Uyarlanabilir Bulanık Sinir A Ăları Sistemi (Adaptive Neuro-Fuzzy Inference System-ANFIS)}

Uyarlanabilir bulanık sinir ağları sistemi - ANFIS (Adaptive Network Based Fuzzy Inference System) Şekil 1'de görüldüğü gibi katmanlar halinde buluınan noktaların birleşimi ile oluşmaktadır. İlk katmanda girişler, son katmanda ise çıkışlar yer almaktadır. Anfis sisteminin yapısı içerisinde hem yapay sinir ağları hem de bulanık mantık yaklaşımı yer almaktadır.

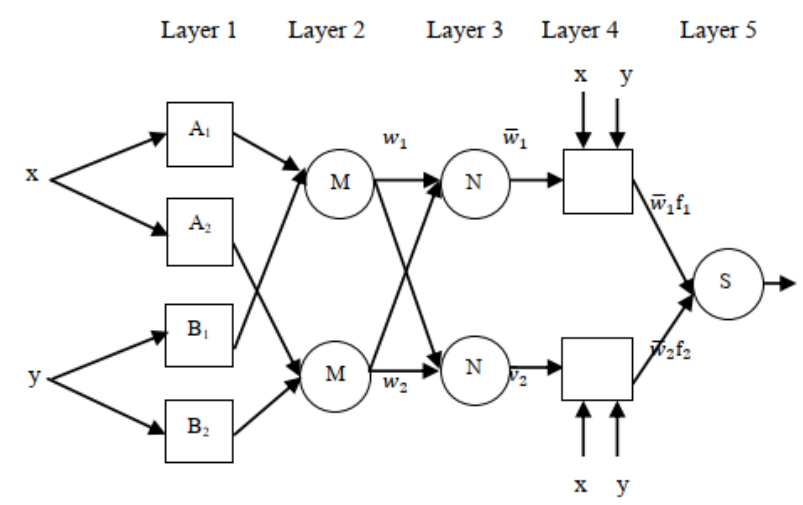

Şekil 1. İki girişli ve iki kuralı bulunan bir ANFIS yapis1

(Anfis structure with two inputs and two rules.) 
Anfis sisteminde veri seti eğitim ve test şeklinde bölünmektedir. Sistem eğitim verileri ile öğrenmektedir. Gerçek değer ile tahmin edilen değer arasındaki fark olan hata değerine göre optimum ayarlamalar gerçekleştirilmektedir. Sistemin en son haline göre de test verileri değerlendirilerek sistemin başarısı elde edilmektedir [15-16].

\section{YÖNTEM (METHOD)}

\subsection{Veri Seti (Data Set)}

UCI Makine Öğrenme Havuzu makine öğrenme topluluklarının makine öğrenme algoritmalarının ampirik analizi için kullandığı veri tabanları, alan teorileri ve veri jeneratörlerinin bir koleksiyonudur. 1000 'den fazla atıf yapılması ve tüm bilgisayar bilimlerinde en çok kullanılan 100 "bildiri”" arasında yer almaktadir.

$\mathrm{Bu}$ çalışmada kullanılan Cleveland Klinik veri kümesi 303 hasta kaydından oluşmaktadır. Veritabanında 76 tane özellik bulunmakta olup bunların sadece 14'ü bilimsel araştırmalarda yaygın bir şekilde kullanılmaktadır [21].

$\mathrm{Bu}$ çalışmada kullanılan veri setine ait özellikler Tablo 1 'de verilmiştir.

Tablo 1. Kalp hastalığı veri seti özellikleri (Dataset features of heart disease)

\begin{tabular}{|c|c|}
\hline Öznitelik & Aralığı \\
\hline Yaş & Sürekli \\
\hline Cinsiyet & 0 : erkek 1:bayan \\
\hline Göğüs ağrısı tipi & 1 ile 4 aras 1 \\
\hline $\begin{array}{l}\text { Dinlenme durumunda kan basıncı } \\
\text { (tansiyon) }\end{array}$ & Sürekli \\
\hline Serum kolesterol (mg/dl) & Sürekli \\
\hline Tokluk şekeri düzeyi > $120 \mathrm{mg} / \mathrm{dl}$ & $1=$ doğru $0=$ yanlış \\
\hline $\begin{array}{lr}\text { Dinlenme } & \text { durumunda } \\
\text { Elektrokardiyografi } & \text { düzeyi } \\
(0,1,2) & \\
\end{array}$ & 1 ile 2 aras 1 \\
\hline Maksimum kalp atış ritmi & Sürekli \\
\hline Egzersiz ile oluşan göğüs ağrısı & $1=$ evet $0:=$ hayır \\
\hline Dinlenme durumunda ST değeri & Sürekli \\
\hline $\begin{array}{l}\text { Pik egzersiz durumunda } \mathrm{ST} \\
\text { segmentinin eğimi }\end{array}$ & 1 ile 2 aras 1 \\
\hline Büyük damarların sayısı (0-3) & Sürekli \\
\hline $\begin{array}{l}\text { Hasar Oranı: } 3=\text { normal; } 6= \\
\text { kalıcı hasar; } 7=\text { geri çevrilebilir } \\
\text { hasar }\end{array}$ & $3,6,7$ \\
\hline
\end{tabular}

Veri seti içerisindeki bağımlı değişken ise kişinin kalp hastalığının bulunup bulunmadığını belirtmektedir ve buna göre 0 ya da 1 değerini almaktadır.

\section{2. Önerilen Yöntem (Proposed Method)}

$\mathrm{Bu}$ çalışmada kalp hastalıklarının tespit edilmesinde başarı oranının artırılması için önerilen algoritma Şekil 1' de gösterilmiştir.

Burada önerilen yöntemin temel dayanağ bulanık küme değerlerinin kullanılmasıdır. Yani temel bileşenler analizinde olduğu gibi aslında bir nevi boyut azaltma işlemi yapılarak verilere farklı bir bakış açısı ile yaklaşılması ve Anfis sisteminin bu bakış açısından elde edilen değerlerin kullanılması ile başarı oranının artırılmasının sağlanmasıdır.

Literatürde bu noktada hem temel bileşenler analizi hem de bulanık kümeleme ile bu işlemin farklı türdeki verisetleri ile kullanımına ilişkin örnekler de vardır [22-23].

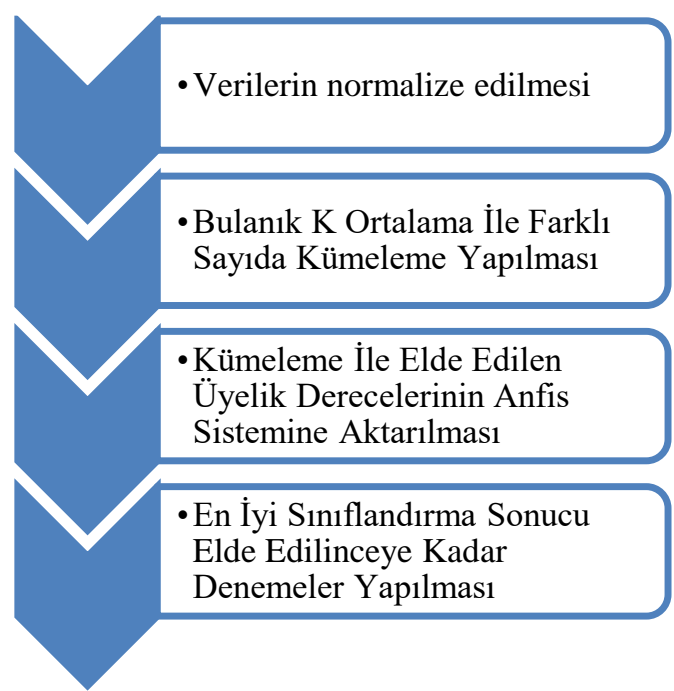

Şekil 2. Çalışma kapsamında önerilen algoritma adımları

(Suggested algorithm steps in working context.)

Şeki 2'de görüldüğü gibi öncelikle verilerin normalize edilmesi ile süreç başlatılmıştır. Tüm veriler Matlab programı kullanılarak 0-1 aralığına normalize edilmiștir. Veriler normalize edildikten sonra Matlab programında Bulanık K Ortalamalar yöntemi kullanılarak veriler değişik sayıda kümelere ayrılmıştır. Farklı sayılarda kümelere ayrılmasının nedeni elde edilen küme üyelik derecelerinin ANFIS sisteminde modelin eğitilmesi ve başarı sonuçlarının karşılaştırılmasında kullanılacak olmasıdır.

Bulanık K Ortalamalar ile elde edilen üyelik derecelerine ait değerler Tablo 2'de verilmiştir. Burada tüm verilerin değil beş adet veriye ait üyelik değerleri gösterilmiştir. Burada verilen değerler küme sayısının iki olduğu duruma aittir. Küme sayısındaki artışa bağlı olarak verilerin üyelik değerleri ve sayıları da değişecektir. 
Tablo 2. İlk beş veriye ait kümelendirme üyelik değerleri

(Cluster membership values for the first five data)

\begin{tabular}{|c|c|c|}
\hline $\begin{array}{c}\text { Veri } \\
\text { No }\end{array}$ & Küme1 üyelik & Küme2 üyelik \\
\hline 1 & 0,575951 & 0,424049 \\
\hline 2 & 0,615484 & 0,384516 \\
\hline 3 & 0,772243 & 0,227757 \\
\hline 4 & 0,782518 & 0,217482 \\
\hline 5 & 0,567299 & 0,432701 \\
\hline
\end{tabular}

Verilerin kümelendirme işlemlerinin tamamlanmasının ardından elde edilen üyelik dereceleri değerleri ANFIS sistemine aktarılmıştır. ANFIS bu verilerle eğitilerek kişinin kalp hastalığının olup olmadığının tahmini gerçekleştirilmiştir. ANFIS sisteminde veri setinin küme sayısına göre elde edilen başarı değerleri ise Tablo 3'de verilmiştir.

Tablo 3. Küme sayılarına göre Anfis başarı oranları

(Anfis success rates according to the number of clusters)

\begin{tabular}{|c|c|}
\hline Küme sayıs1 & ANFIS başarı oranı (yüzde) \\
\hline 2 & 0,96 \\
\hline 3 & 0,88 \\
\hline 4 & 0,92 \\
\hline 5 & 0,99 \\
\hline
\end{tabular}

Tablo 3 incelendiği zaman küme sayısındaki artışa bağlı olarak ANFIS sisteminin başarı oranında azalma olsada en iyi sonuçları verilerin 5 kümeye ayrılması sonucunda elde edilen üyelik dereceleri ile elde edebilmiştir.

\section{BULGULAR (FINDINGS)}

ANFIS sistemi tarafından oluşturulan sonuçların dağılımı ise Şekil 2'de verilmiştir. Sonuç değişkeni kategorik olduğu için ANFIS tarafından üretilen sonuçlar bir kesim değeri ile kategorik yapılmıştır. Burada kesim değeri olarak 0.5 değeri kullanılmış bu değerin altındakiler 0 ve üstündeki değerler ise 1 olarak elde edilmiştir. $\mathrm{Bu}$ sayede sistemin başarı oranı elde edilebilmiştir.

Şekil 3'de görüldüğü gibi Anfis sisteminin ürettiği tahmin değerleri bağımlı değişken olan kalp hastalığının olup olmama durumunu rahatlıkla ayırabilecek şekilde oluştuğu gözlemlenmiştir.

Oluşturulan ANFIS sistemine ait çalışma arabirimi Şekil 4'de verilmiştir. İki giriş bulunan ANFIS sistemi girişlerine verilen değerleri kullanarak çıkış değişkeninin değerini rahatlıkla tahmin edebilmektedir.

Anfis sistem gereği bulanık kurallar tabanlı çalışan bir sistemdir. Verilere göre oluşturulan kurallar kullanılarak sistem tahminde bulunmaktadır. Sistem tarafından oluşturulan kurallardan on iki tanesi Şekil 4'de verilmiştir. Sistemde toplam 32 kural bulunmaktadır. Sistemin beş adet girişi ve her girişin iki adet üyelik değeri bulunmasından dolayı $2^{5}=32$ olmasindan dolayı Anfis 32 adet kural ile çalışmaktadır.

Şekil 4'de verilen kurallardan bir tanesi de açıkça şu şekilde yazılabilir.

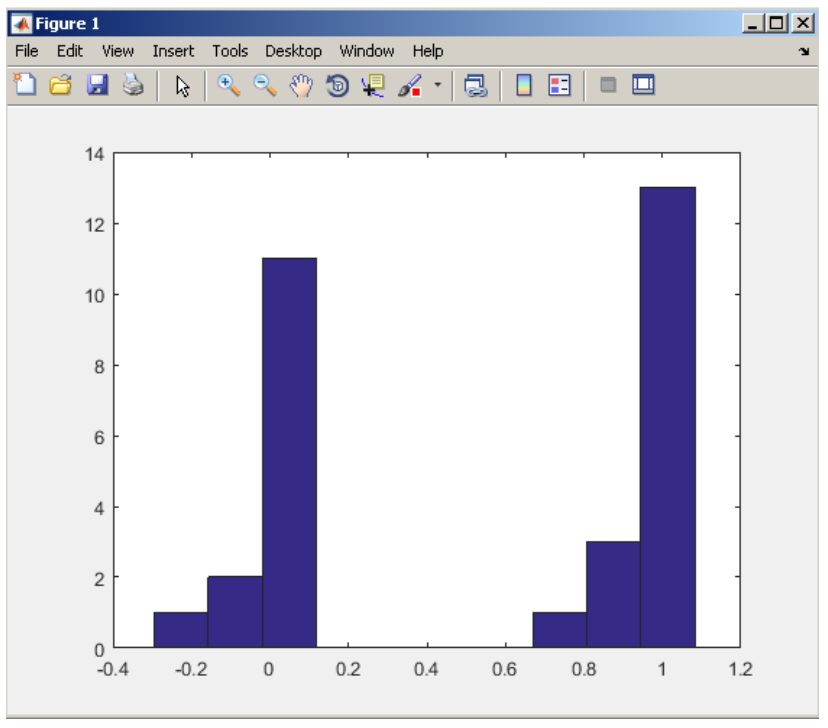

Şekil 3. Anfis tahminlerinin dağılımı

(The distribution of Anfis prediction)

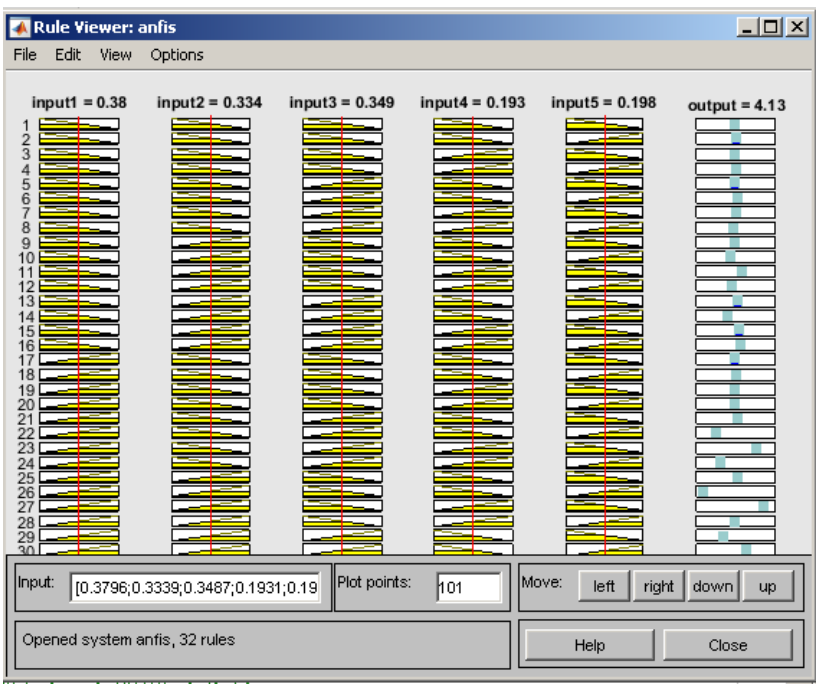

Şekil 4. Anfis sisteminin yapısı

(The structure of the anfis system)

If (input 1 is in $1 \mathrm{mf} 1)$ and (input 2 is in $2 \mathrm{mf} 1)$ and (input 3 is in $3 \mathrm{mf} 1$ ) and (input4 is in $4 \mathrm{mf} 1$ ) and (input5 is in $5 \mathrm{mf} 1$ ) then (output is out $1 \mathrm{mf} 1$ ) (1)

$\mathrm{Bu}$ şekilde kurallardan oluşan sisteme ait kural listesinin bir örneği Şekil 5'de gösterilmiştir. 


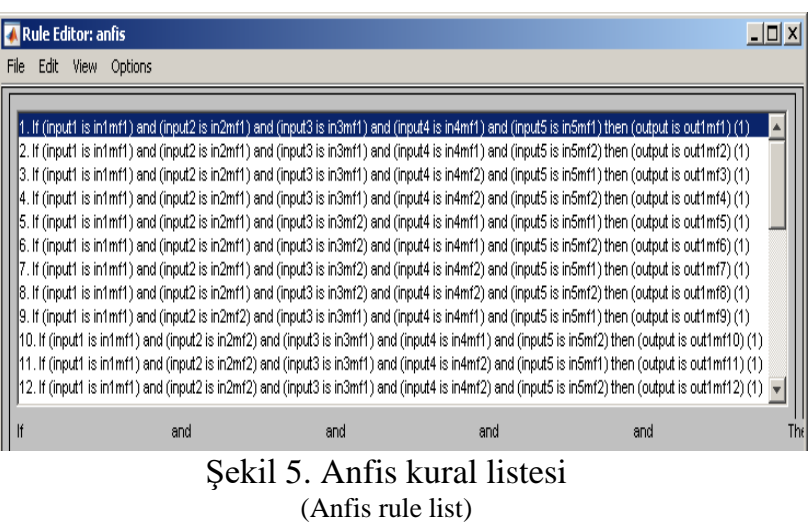

Anfis sisteminin giriş ve çıkışlarının görüntülendiği ve üyelik fonksiyonlarının düzenlendiği ekran ise Şekil 6'da verilmiştir. Buradan sistemin giriş ve çıkış üyelik fonksiyonları ve parametreleri üzerinde değişiklik yap1labilmektedir.

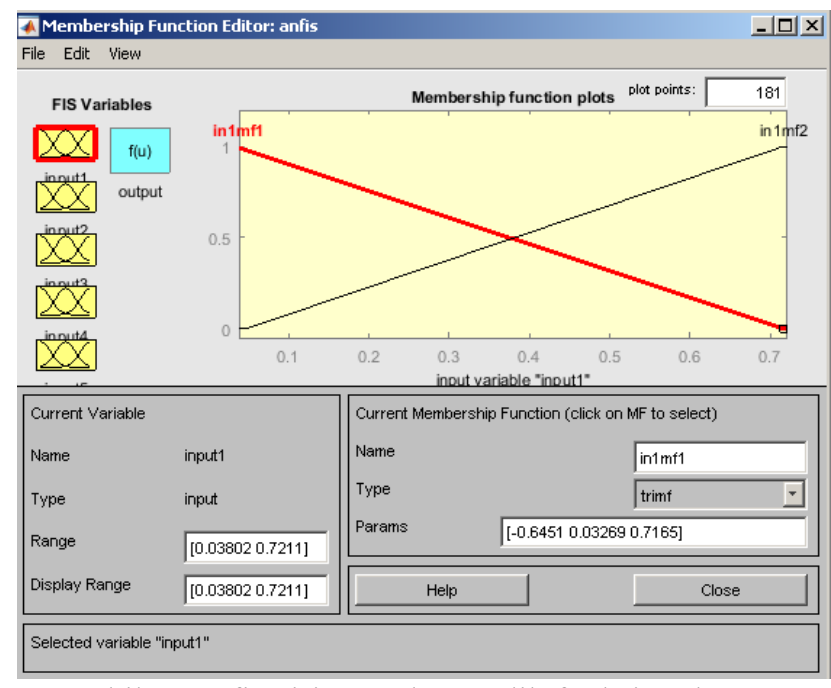

Şekil 6. Anfis giriş ve çıkış üyelik fonksiyonları (Anfis input and output membership functions)

$\mathrm{Bu}$ çalışmada ANFIS sisteminin başarısı K kat çarpraz geçerlilik sınaması ile tespit edilmiştir. Yani veriler 10 parçaya bölünerek her aşamada bir parçanın test verisi olması sağlanmış ve 10 adımda elde edilen başarıların ortalaması alınmıştır.

Çalışmada test verileri üzerinden sistemin karşılaştırılabilmesi için Tablo 4'de gösterilen bir formatı bulunan karşılaştırma matrisi kullanılmıştır. Bu matris üzerinden hesaplanan değerler ile sistemin başarısı test edilmiştir.

Tablo 4. Karışıklık matrisi (Confusion matrix)

\begin{tabular}{|c|l|l|l|}
\hline \multicolumn{2}{|c|}{} & \multicolumn{2}{c|}{ Tahmin } \\
\cline { 3 - 4 } \multicolumn{2}{|c|}{} & Olumlu & Olumsuz \\
\hline $\begin{array}{c}\text { Var olan } \\
\text { durum }\end{array}$ & Doğru & TP & FN \\
\cline { 2 - 4 } & Yanlış & FP & TN \\
\hline
\end{tabular}

Tablo 4'de gösterilen kısaltmalar ise şu şekildedir [24].
TP (True Positive - Doğru Pozitif): Gerçekte doğruyken doğru olarak sınıflandırılan kayıt sayısı TN (True Negative - Doğru Negatif): Gerçekte yanlışken yanlış olarak sınıflandırılan kayıt sayısı FP (False Positive - Yanlış Pozitif): Gerçekte yanlışken doğru olarak sınıflandırılan kayıt sayısı FN (False Negative - Yanlış Negatif): Gerçekte doğruyken yanlış olarak sınıflandırılan kayıt sayısı

Tablo 4'de gösterilen matris kullanılarak test verilerinin sınıflandırma değerlendirmesi için yaygın olarak kullanılan ölçüm değerleri hesaplanmıştır. Bu değerlerin nasıl hesaplandiğı (1), (2), (3), (4) ve (5) denklemleri ile Matlab programında hesaplanmıştır [25-26].

Doğruluk $($ accuracy $)=\mathrm{TP}+\mathrm{TN} /(\mathrm{TP}+\mathrm{TN}+\mathrm{FP}+\mathrm{FN})$

Hassaslik $($ recall $)=\mathrm{TP} /(\mathrm{TP}+\mathrm{FN})$

Kesinlik $($ precision $)=\mathrm{TP} / \mathrm{TP}+\mathrm{FP}$

$\mathrm{F}_{1}=2 *$ kesinlik*hassaslık / (kesinlik+hassasl1k)

Çalışma sonucunda elde edilen sınıflandırma ölçüm değerleri Tablo 5'de verilmiştir.

Tablo 5. Sınıflandırma ölçümleri (Classification metrics)

\begin{tabular}{|c|c|}
\hline Sinıflandırma ölçümü & Değer \\
\hline Doğruluk & 0,99335 \\
\hline Hassaslık & 0,9868 \\
\hline Kesinlik & 0,9803 \\
\hline $\mathrm{F}_{1}$ & 0,9835 \\
\hline
\end{tabular}

$\mathrm{Bu}$ çalışmada ANFIS sisteminin başarısı K katlamalı çarpraz doğrulama sınaması ile tespit edilmiştir. Yani veriler 10 parçaya bölünerek her aşamada bir parçanın test verisi olması sağlanmış ve 10 adımda elde edilen başarıların ortalaması alınmıştır.

Sınıflandırma başarısının değerlendirilmesindeki bir diğer önemli unsurda ROC Eğrisidir. Bu eğri hassaslık ve 1-kesinlik değerlerinin belirli eşik değerleri baz alınarak grafikte bir araya getirilmesi ile oluşur. Bu eğri de refesans çizgisi olarak alınan köşegen üzerinde bulunan çizgi verilerin tesadüfü sınıflandırıldığını gösterir. $\mathrm{Bu}$ eğri üzerinde sol üst köşeye eğrinin yaklaşması sınıflandırmanın oldukça başarılı olduğunun göstergesidir. Bu bağlamda eğrinin altında kalan ne kadar büyük ise sınıflandırma da o kadar başarılıdır. $\mathrm{Bu}$ çalışmada ROC eğrisi SPSS programı ile çizdirilmiştir. SPSS programı sonucunda sınıfların dağılımı ve ROC eğrisi sonuçları şekil olarak Şekil 7'de verilmiştir.

Case Processing Summary
\begin{tabular}{|l|r|}
\hline VAR00010 & $\begin{array}{c}\text { Valid N } \\
\text { (listwise) }\end{array}$ \\
\hline Positive $^{\mathrm{b}}$ & 165 \\
Negative $_{n n}$ & 138 \\
\end{tabular}

Şekil 7. ROC eğrisi sonuçları (ROC curve results) 
SPSS programı ile çizdirilen ROC eğrisi ise Şekil 8'de verilmiştir.

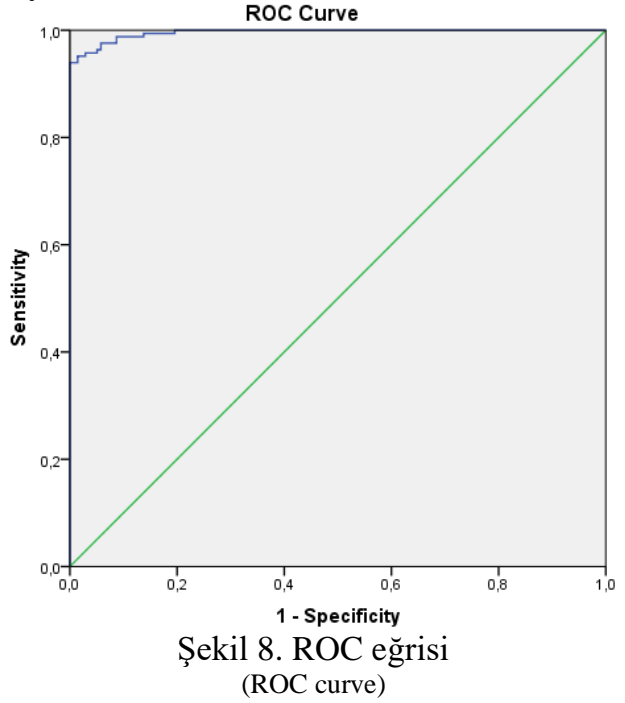

\section{SONUÇLAR (RESULTS)}

Literatürde kalp hastalıklarının tahmini ile ilgili yapılan çalışmalar yüzde olarak 60 ile 92 arasında bir başarı oranı ile yer almaktadır. Ancak kalp hastalıkları gibi insan sağlığı ile ilgili konularda bu başarı oranlarının artırılması hayati önem taşımaktadır. Bu çalışma bu başarı oranının Anfis ve Bulanık $\mathrm{K}$ ortalamalar yöntemi ile artırılabileceğini düşüncesi ile gerçekleştirilmiştir.

Literatürde ANFIS sisteminin kullanılarak kalp hastalıklarının tahmin edildiği çalışmada tüm değişkenler kullanılmayarak oluşturulan sistemde başarı oranı yüzde olarak 92,30 bulunmuştur (Ziasabounchi ve Askerzade, 2014). Bu çalışmada bu başarı oranın artırılması ve tüm değişkenlerin kullanıldığı etkin bir model önerilmiştir.

Önerilen modelde sistemde bulunan değişkenler kullanılarak bulanık $\mathrm{k}$ ortalamalar yöntemi ile bir kümeleme gerçekleştirilmiştir. Gerçekleştirilen kümeleme işlemi sonucunda elde edilen kümelere ait üyelik dereceleri ANFIS sisteminin modellenmesi ve eğitilmesinde kullanılmıştır. 10 kat çaprazlama tekniği kullanılarak modelin başarısı ölçülmüş ve başarı oranının \%9835 olduğu tespit edilmiștir. $\mathrm{Bu}$ oran literatürde aynı veri seti ile gerçekleştirilen çalışmalarla kıyaslandığında başarıda ciddi bir artış olduğu görülmüştür.

$\mathrm{Bu}$ çalışmaya yöntem bakımından en çok benzeyen çalışma [11], ANFIS sistemi kullanarak elde edilen başarının literatürde yer alan birçok çalışmaya göre örneğin [7] [27] daha yüksek başarı sağladığını tespit etmiştir. Aynı veritabanını kullanarak ilerleyen yıllarda da benzer çalışmalar yapılmasından dolayı daha sonraki yıllarda da gerçekleştirilen çalışmalar ve başarı oranları Tablo 6'da verilmiştir.

Tablo 5'de görüldüğü gibi son yıllarda aynı veritabanı üzerinde gerçekleştirilen çalışmalar incelendiği zaman başarı oranlarının bu çalışmada elde edilen başarı oranı olan \%9835 değerinin altında olduğu görülmektedir.

Tablo 6. Kalp hastalığı tahmini ile ilgili çalışmalar ve başarı oranları

(Studies and success rates related to heart disease prediction)

\begin{tabular}{|l|l|l|}
\hline Yöntem & Doğruluk & Referans \\
\hline Anfis & 0,9230 & {$[11]$} \\
\hline $\begin{array}{l}\text { Flda ile } \\
\text { Ensemble } \\
\text { yöntem }\end{array}$ & 0,9207 & {$[28]$} \\
\hline $\begin{array}{l}\text { Destek Vektör } \\
\text { Makineleri }\end{array}$ & 0,9167 & {$[29]$} \\
\hline $\begin{array}{l}\text { Destek Vektör } \\
\text { Makineleri }\end{array}$ & 08947 & {$[5]$} \\
\hline $\begin{array}{l}\text { Çok katmanlı } \\
\text { YSA }\end{array}$ & 0,8349 & {$[30]$} \\
\hline
\end{tabular}

2014 yılında Anfis ile aynı veritabanı ile gerçekleştirilen çalışma ve 2019 ile 2020 yıllarında hem ulusal hem de uluslararsı dergilerde yayınlanmış çalışmalarda başarı oranlarının yüzde olarak 92 civarlarında olduğu görülmektedir. Özellikle tüm makine öğrenme algoritmaları ve öznitelik seçim yöntemlerinin kullanılarak kalp hastalığı tahmini yapılan [16] çalışmada doğrusal diskriminant analizi ve Ensemble (topluluk) yöntemler kullanılmasına rağmen en yüksek başarı yüzde olarak 92 olmuştur.

Bu çalışmada elde edilen sonuçlar bulanık kümeleme işlemlerinin öznitelik seçme ve boyut azaltma algoritmalarına göre veriyi temsil eden yapıyı daha iyi açıklayabildiğini ve bu sayede sınıflandırma başarısını oldukça artırdığı gözlemlenmiştir.

Bundan dolayı bu çalışmada önerilen yöntemin kalp hastalıklarının tahmininde yüksek başarı oranı ile kullanılabileceği düşünülmektedir.

\section{KAYNAKLAR (REFERENCES)}

[1] İnternet: Acıbadem Hastanesi, Kalp Hastalıkları, https://www.acibadem.com.tr/ilgi-alani/kalphastaliklari/\#undefined, 02.05.2020.

[2] İnternet: World Heart Federation (W. H. F.), Different heart diseases., $\quad$ https://www.world-heartfederation.org/resources/different-heart-diseases/., 02.05.2020.

[3] A. Arı, Yapay Sinir Ağları Kullanılarak Kalp Hastalığının Öngörülmesi, Yüksek Lisans Tezi, Dokuz Eylül Üniversitesi Fen Bilimleri Enstitüsü, İzmir, 2019.

[4] A. H. Chen, S. Y. Huang, P. S. Hong, , C. H. Cheng, E. J. Lin, "HDPS: Heart Disease Prediction System" Computing in Cardiology, 557-560, 2011.

[5] Ö. Özmen, K. Ahmad, A. Engin, "Sinıflandırıcıların Kalp Hastalığı Verileri Üzerine Performans Karşılaştırması", Fırat Üniversitesi Mühendislik Bilimleri Dergisi, 30(3), 153-159, 2018. 
[6] M. E. Taşçı, R. Şamlı, "Veri Madenciliği İle Kalp Hastalığı Teşhisi”, Avrupa Bilim ve Teknoloji Dergisi, (Özel Sayı), 8895, 2020.

[7] H. Kahramanli, N. Allahverdi, "Design of a Hybrid System for the Diabetes and Heart Diseases", Expert Systems with Applications, $\quad 35, \quad 82-89$. http://dx.doi.org/10.1016/j.eswa.2007.06.004, 2008.

[8] M.L Sharan, K.B. Sathees, "Analysis of Cardiovascular Heart Disease Prediction Using Data Mining Techniques", Analysis, 4(1), 55-58, 2016.

[9] Z. Jin, Y. Sun, A.C. Cheng, "Predicting cardiovascular disease from real-time electrocardiographic monitoring: An adaptive machine learning approach on a cell phone", Annual International Conference of the IEEE Engineering in Medicine and Biology Society, 6889-6892, 2009.

[10] F. Bulut, "AdaBoost ile Kalp Krizi Risk Tespiti”, Celal Bayar Üniversitesi Fen Bilimleri Dergi, 12(3), 459-472, 2016.

[11] N. Ziasabounchi, I. Askerzade, "ANFIS based classification model for heart disease prediction", International Journal of Electrical \& Computer Sciences IJECS-IJENS, 14(02), 7-12, 2014.

[12] M. Bıyan, "Bulanık Mantık Tabanlı Çalışan Disiplin Kurulu Yazılımının Gerçekleştirilmesi”, Çankırı Karatekin Üniversitesi Sosyal Bilimler Enstitüsü Dergisi, 7(1), 819-842.

[13] M. F. Rian, M. N. Surya, \& A. N. Ratna, "Health monitoring application using fuzzy logic based on android", Journal of Physics: Conference Series, 1192(1) , 2019.

[14] N. Dalevska, V. Khobta, A. Kwilinski, \& S. Kravchenko, "A model for estimating social and economic indicators of sustainable development", Entrepreneurship and Sustainability Issues, 6(4), 1839-1860, 2019.

[15] S. S. Sari, \& Ş. Y. Yiğiter, "Borsa Istanbul Hisse Senedi Getirilerinin ANFIS Aracılığıyla Tahmin Edilmesi”, Bingöl Üniversitesi İktisadi ve İdari Bilimler Fakültesi Dergisi, 4(1), 171-193,2020.

[16] M. T. Arslan, \& B. Haznedar, "Prostat Kanseri Gen İfade Profilinin ANFIS İle Sinıflandırılması”, 1st International Mediterranean Science and Engineering Congress (IMSEC 2016), Adana/Turkey, 2016.

[17] P. A. Adedeji, S. O. Masebinu, S. A. Akinlabi \& N. Madushele, "Adaptive Neuro-fuzzy Inference System (ANFIS) Modelling in Energy System and Water Resources", Optimization Using Evolutionary Algorithms and Metaheuristics: Applications in Engineering, 117, 2019.

[18] S. Giray, Ö. Yorulmaz \& Ö. Ergüt, "Ülkelerin Gini Katsayisi, Göç, Suç Ve Mutluluk Değişkenleri Açisindan Bulanik Ve Dayanikli Kümeleme Metotlari İle Siniflandirilmasi”, Journal Of Awareness, 1(2), 1-16, 2016.
[19] S. İlkin, O. Aytar, T. H. Gençtürk, \& S. Şahin, "Dermoskopik Görüntülerde Lezyon Bölütleme İşlemlerinde K-Ortalama Kümeleme Algoritmasının Kullanımı", Gazi Üniversitesi Fen Bilimleri Dergisi Part C: Tasartm Ve Teknoloji, 8(1), 182191

[20] O. P. Mahela, B. Khan, B, H. H. Alhelou, \& P. Siano, "Power quality assessment and event detection in distribution network with wind energy penetration using stockwell transform and fuzzy clustering", IEEE Transactions on Industrial Informatics, 16(11), 6922-6932, 2020.

[21] İnternet:: UCI Machine Learning Repository, U. 1988, Heart disease data set, https://archive.ics.uci.edu/ml/datasets/heart+Disease., 03.03.2020.

[22] E. İsen, Anfis Ve Bulanık C-Ortalamalar Yöntemleri Tabanlı Çok Kriterli Envanter Sınıflandırma Modeli, Yüksek Lisans Tezi, Sakarya Üniversitesi, Fen Bilimleri Enstitüsü, 2017.

[23] M. Karabatak, , M. C. İnce, E. Avc1, "Göğüs kanseri için temel bileşen analizi yöntemi tabanlı uzman teşhis sistemi”, IEEE 16. Sinyal İşleme ve İletişim Uygulamaları Kutultayı, Didim-Aydın, 2008.

[24] G. Akgül, A. A. Çelik, Z. E. Aydın, \& Z. K. Öztürk, "Hipotiroidi Hastalı̆̆ Teşhisinde Sınıflandırma Algoritmalarının Kullanımı”, Bilişsim Teknolojileri Dergisi, 13(3), 255-268, 2020.

[25] M. Samet, O. Çakır, O. Bayat, D. G. Duru, \& A. D. Duru, "Gözbebeği Hareketleri Temelli Duygu Durumu Sınıflandırılması”, Bilişim Teknolojileri Dergisi, 13(2), 137144, 2020.

[26] Ç. Ac1, A. Çırak, "Türkçe Haber Metinlerinin Konvolüsyonel Sinir Ağları Ve Word2Vec Kullanılarak Sinıflandırılması", Bilişim Teknolojileri Dergisi , 12 (3) , 219-228, 2019.

[27] M. Shouman, T. Tuner, R. Stocker, "Using data mining techniques in heart disease diagnosis and treatment", International Conference onCommunications and Computers, 173-177, 2012.

[28] B. Kolukısa, , H. Hacılar, M. Kuş, B. Bakır-Güngör, A. Aral, V. Ç. Güngör, "Diagnosis of Coronary Heart Disease via Classification Algorithms and a New Feature Selection Methodology", International Journal of Data Mining Science, 1(1), 8-15, 2019.

[29] İ. Özcan, B. Tasar, A. B. Tatar, O. Yakut, "Destek Vektör Makinasi Algoritması İle Kalp Hastalıklarının Tahmini”, Bilgisayar Bilimleri, 4(2), 74-79, 2019.

[30] Ş. Cihan, B. Karabulut, G. Arslan, G. Cihan, "Koroner Arter Hastalı̆̆1 Riskinin Veri Madenciliği Yöntemleri İle İncelenmesi”, Uluslararası Mühendislik Araştırma Ve Gelişstirme Dergisi, 10(1), 85-93, 2018. 